\title{
Experimental adaptation of an influenza H5 HA confers respiratory droplet transmission to a reassortant $\mathrm{H} 5 \mathrm{HA} / \mathrm{H} 1 \mathrm{~N} 1$ virus in ferrets
}

\author{
Masaki Imai ${ }^{1}$, Tokiko Watanabe ${ }^{1,2}$, Masato Hatta ${ }^{1}$, Subash C. Das ${ }^{1}$, Makoto Ozawa ${ }^{1,3}$, Kyoko Shinya ${ }^{4}$, Gongxun Zhong ${ }^{1}$, \\ Anthony Hanson ${ }^{1}$, Hiroaki Katsura ${ }^{5}$, Shinji Watanabe ${ }^{1,2}$, Chengjun $\mathrm{Li}^{1}$, Eiryo Kawakami ${ }^{2}$, Shinya Yamada ${ }^{5}$, Maki Kiso ${ }^{5}$, \\ Yasuo Suzuki ${ }^{6}$, Eileen A. Maher ${ }^{1}$, Gabriele Neumann ${ }^{1}$ \& Yoshihiro Kawaoka ${ }^{1,2,3,5}$
}

\begin{abstract}
Highly pathogenic avian $\mathrm{H} 5 \mathrm{~N} 1$ influenza A viruses occasionally infect humans, but currently do not transmit efficiently among humans. The viral haemagglutinin (HA) protein is a known host-range determinant as it mediates virus binding to hostspecific cellular receptors ${ }^{1-3}$. Here we assess the molecular changes in HA that would allow a virus possessing subtype H5 HA to be transmissible among mammals. We identified a reassortant $\mathrm{H} 5$ $\mathrm{HA} / \mathrm{H} 1 \mathrm{~N} 1$ virus-comprising $\mathrm{H} 5 \mathrm{HA}$ (from an $\mathrm{H} 5 \mathrm{~N} 1$ virus) with four mutations and the remaining seven gene segments from a 2009 pandemic $\mathrm{H} 1 \mathrm{~N} 1$ virus - that was capable of droplet transmission in a ferret model. The transmissible $\mathrm{H} 5$ reassortant virus preferentially recognized human-type receptors, replicated efficiently in ferrets, caused lung lesions and weight loss, but was not highly pathogenic and did not cause mortality. These results indicate that H5 HA can convert to an HA that supports efficient viral transmission in mammals; however, we do not know whether the four mutations in the H5 HA identified here would render a wholly avian $\mathrm{H} 5 \mathrm{~N} 1$ virus transmissible. The genetic origin of the remaining seven viral gene segments may also critically contribute to transmissibility in mammals. Nevertheless, as $\mathrm{H} 5 \mathrm{~N} 1$ viruses continue to evolve and infect humans, receptor-binding variants of $\mathrm{H} 5 \mathrm{~N} 1$ viruses with pandemic potential, including avian-human reassortant viruses as tested here, may emerge. Our findings emphasize the need to prepare for potential pandemics caused by influenza viruses possessing $\mathrm{H} 5 \mathrm{HA}$, and will help individuals conducting surveillance in regions with circulating $\mathrm{H} 5 \mathrm{~N} 1$ viruses to recognize key residues that predict the pandemic potential of isolates, which will inform the development, production and distribution of effective countermeasures.
\end{abstract}

Although $\mathrm{H} 5 \mathrm{~N} 1$ viruses continue to cause outbreaks in poultry and there are cases of human infection in Indonesia, Vietnam, Egypt and elsewhere (http://www.who.int/influenza/human_animal_interface/H5N1_ cumulative_table_archives/en/index.html), they have not acquired the ability to cause human-to-human transmission. Investment in $\mathrm{H} 5 \mathrm{~N} 1$ vaccines has therefore been questioned. However, because humans lack immunity to influenza viruses possessing an $\mathrm{H} 5 \mathrm{HA}$, the emergence of a transmissible H5-HA-possessing virus would probably cause a pandemic. To prepare better for such a scenario, it is critical that we understand the molecular changes that may render H5-HA-possessing viruses transmissible in mammals. Such knowledge would allow us to monitor circulating or newly emerging variants for their pandemic potential, focus eradication efforts on viruses that already have acquired subsets of molecular changes critical for transmission in mammals, stockpile antiviral compounds in regions where such viruses circulate, and initiate vaccine generation and large-scale production before a pandemic. Therefore, we studied the molecular features that would render H5-HA-possessing viruses transmissible in mammals.

Previous studies suggested that HA has a major role in host-range restriction of influenza A viruses ${ }^{1-3}$. The HA of human isolates preferentially recognizes sialic acid linked to galactose by $\alpha 2,6$-linkages (Sia $2,6 \mathrm{Gal}$ ), whereas the HA of avian isolates preferentially recognizes sialic acid linked to galactose by $\alpha 2,3$-linkages (Sia $\alpha 2,3 \mathrm{Gal})^{3}$. A small number of avian $\mathrm{H} 5 \mathrm{~N} 1$ viruses isolated from humans show limited binding to human-type receptors, a property conferred by several amino acid changes in $\mathrm{HA}^{4-9}$. None of the $\mathrm{H} 5 \mathrm{~N} 1$ viruses tested transmitted efficiently in a ferret model ${ }^{10-13}$, although, while our paper was under review, one study ${ }^{14}$ reported that a virus with a mutant $\mathrm{H} 5 \mathrm{HA}$ and a neuraminidase (NA) of a human virus in the H5N1 virus background caused respiratory droplet transmission in one of two contact ferrets.

To identify novel mutations in avian H5 HAs that confer humantype receptor-binding preference, we introduced random mutations into the globular head (amino acids 120-259 (H3 numbering), which includes the receptor-binding pocket) of A/Vietnam/1203/2004 (H5N1; VN1203) HA (Supplementary Fig. 1). Although this virus was isolated from a human, its HA retains avian-type receptor-binding properties $^{6,15}$. We also replaced the multibasic HA cleavage sequence with a non-virulent-type cleavage sequence, allowing us to perform studies in biosafety level 2 containment (http://www.who.int/ csr/resources/publications/influenza/influenzaRMD2003_5.pdf). The mutated polymerase chain reaction (PCR) products were cloned into RNA polymerase I plasmids ${ }^{16}$ containing the VN1203 HA complementary DNA, which resulted in Escherichia coli libraries representing the randomly generated HA variants. Sequence analysis of 48 randomly selected clones indicated an average of 1.0 amino acid changes per HA globular head (data not shown). To generate an $\mathrm{H} 5 \mathrm{~N} 1$ virus library, plasmids for the synthesis of the mutated HA gene and the unmodified NA gene of VN1203 were transfected into human embryonic kidney (293T) cells together with plasmids for the synthesis of the six remaining viral genes of A/Puerto Rico/8/34 (H1N1; PR8), a laboratory-adapted human influenza A virus.

Turkey red blood cells (TRBCs; which possess both Siax2,6Gal and Sia $22,3 \mathrm{Gal}$ on their surface (data not shown)) were treated with Salmonella enterica serovar Typhimurium LT2 sialidase, which preferentially removes $\alpha 2,3$-linked sialic acid (that is, avian-type receptors), creating TRBCs that predominantly possess Sia $2,6 \mathrm{Gal}$ on the cell surface (Sia $\alpha 2,6$-TRBCs; Supplementary Fig. 2). The virus library was then adsorbed to Sia 22,6 -TRBCs at $4{ }^{\circ} \mathrm{C}$ and extensively washed to remove nonspecifically or weakly bound viruses. Bound viruses were eluted by incubation at $37^{\circ} \mathrm{C}$ for $30 \mathrm{~min}$, and then diluted to approximately $\sim 0.5$ viruses per well (on the basis of a pilot experiment that

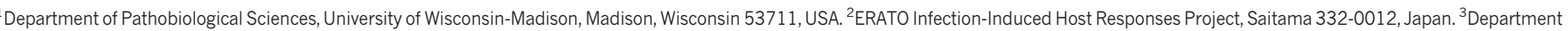

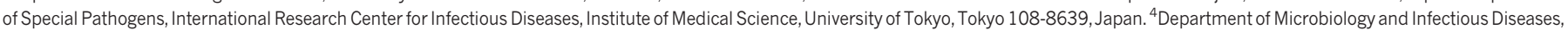

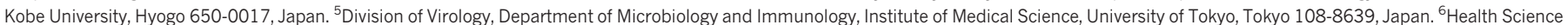
Hills, College of Life and Health Sciences, Chubu University, Kasugai, Aichi 487-8501, Japan. 
assessed the approximate number of eluted viruses). We screened onethird of the library (that is, $2.1 \times 10^{6}$ viruses) in three separate selection experiments (that is, $0.7 \times 10^{6}$ viruses per experiment) and isolated 370 viruses that bound to Sia 2,6-TRBCs (Supplementary Fig. 2). Individual viruses were then grown in Madin-Darby canine kidney (MDCK) cells modified to overexpress Sia 2,6Gal (AX4 cells ${ }^{17}$ ), and screened again for their ability to agglutinate Sia $2,6-T R B C s$ (Supplementary Fig. 2). The parental control virus (designated VN1203/ PR8) with avian-type receptor-binding specificity agglutinated untreated TRBCs (which possess both human- and avian-type receptors on their surface), but not TRBCs possessing predominantly human-type recep-

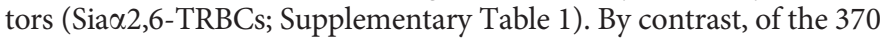
viruses originally isolated, nine agglutinated Sia $2,6-\mathrm{TRBCs}$, albeit with different efficiencies (Supplementary Table 1). All nine viruses possessed mutations in the region targeted for random mutagenesis; one mutant also possessed an additional mutation (E119G) in an area that was not targeted for mutation. Most of the mutations clustered around the receptor-binding pocket (Fig. 1a). Several of the selected viruses possessed mutations known to increase binding to humantype receptors, including N186K (ref. 9), S227N (ref. 5) and Q226L (which confers human-type receptor binding together with G228S) ${ }^{15}$ (all shown in blue in Fig. 1a). The identification of known determinants of human-type receptor-binding specificity from a library of random mutants validates our approach. Notably, our screen also identified mutations not previously associated with receptor-binding specificity.

Although viruses were diluted to $\sim 0.5$ viruses per well for amplification in AX4 cells, we cannot exclude the possibility that some wells were infected with more than one virus, resulting in mixed populations. To confirm the significance of the identified mutations in HA for human-type receptor binding, the mutations were engineered into a VN1203/PR8 virus (possessing an avirulent HA cleavage site sequence, as described earlier). All nine mutants were generated; however, after two passages in MDCK cells, the S136N mutation reverted to the wildtype sequence. This mutant was excluded from further evaluation.

First, we confirmed the binding of the remaining eight variants to Sias2,6-TRBCs (Supplementary Table 1). For comparison, we included a VN1203/PR8 virus with two changes in its HA (Q226L and G228S) previously shown to have increased binding to $\mathrm{Sia} \alpha 2,6 \mathrm{Gal}^{6,15}$. Indeed, compared to the wild-type VN1203/PR8 virus, the Q226L/G228S mutant displayed an increased ability to bind to human-type receptors. For the recreated variants, haemagglutination titres were higher and slightly different from the initial characterization, which we attribute to biological differences (the initial characterization was carried out with non-concentrated cell culture supernatant and potentially mixed virus populations, whereas the recreated viruses were concentrated and purified) and to experimental differences (that is, differences between the TRBC batches or the efficiency of $\alpha 2,3$ sialidase treatment, or both). Collectively, however, these experiments demonstrate that this random mutagenesis approach allows the identification of hitherto unrecognized amino acid substitutions that permit avian virus HAs to bind to human-type receptors.

To characterize further the receptor-binding properties of the selected variants, we used solid-phase binding assays in which sialylglycopolymers were absorbed to plates, which were then incubated with virus (Fig. 2a). A virus possessing the HA and NA genes of the seasonal human A/Kawasaki/173/2001 (H1N1; K173) virus and the remaining genes from PR8 (K173/PR8) served as a control virus with typical human-type receptor specificity. Indeed, K173/PR8 preferentially bound to Sia 2 2,6Gal. In contrast, VN1203/ PR8 bound to only Sia $2,3 \mathrm{Gal}$. As reported elsewhere ${ }^{6,15}$, the Q226L/ G228S mutations led to increased binding to Sia $\alpha 2,6 \mathrm{Gal}$. Variants I202T/R220S, W153R/T160I, N169I/H184L/I217M and H130Q/ K157E resembled VN1203/PR8 in their binding to glycans, despite the fact that these mutants weakly agglutinated Sia 2,6 -TRBCs (see Supplementary Table 1). These viruses may have bound to glycans on TRBCs that were different from Sia $2,6 \mathrm{Gal} \beta 1,4 \mathrm{GlcNAc}$ used in this study. However, variants N186K/M230I, S227N/G228A and Q226L/ E231G showed an appreciable increase in binding to Sia 2,6Gal but also retained binding capacity for Sia 2,3Gal. Of all of the variants tested, only E119G/V152I/N224K/Q226L exhibited specificity for only Sia 2 2,6Gal. Thus, only one H5 HA variant with receptor-binding capability akin to that of seasonal influenza viruses was isolated from the library screen of $2.1 \times 10^{6}$ viruses. To identify the amino acid change(s) responsible for the conversion from Sia 22,3Gal to Sia 2 2,6Gal recognition in the E119G/V152I/N224K/Q226L virus $\mathrm{HA}$, we tested the amino acid changes at positions 119, 152, 224 and 226 individually and in various combinations. Solid-phase binding assays demonstrated that the N224K/Q226L combination is critical for the shift from Sia $2,3 \mathrm{Gal}$ to Sia $\alpha 2,6 \mathrm{Gal}$ recognition (Fig. 2b); Q226L in combination with V152I also conferred weak binding to $\alpha 2,6$-glycans.
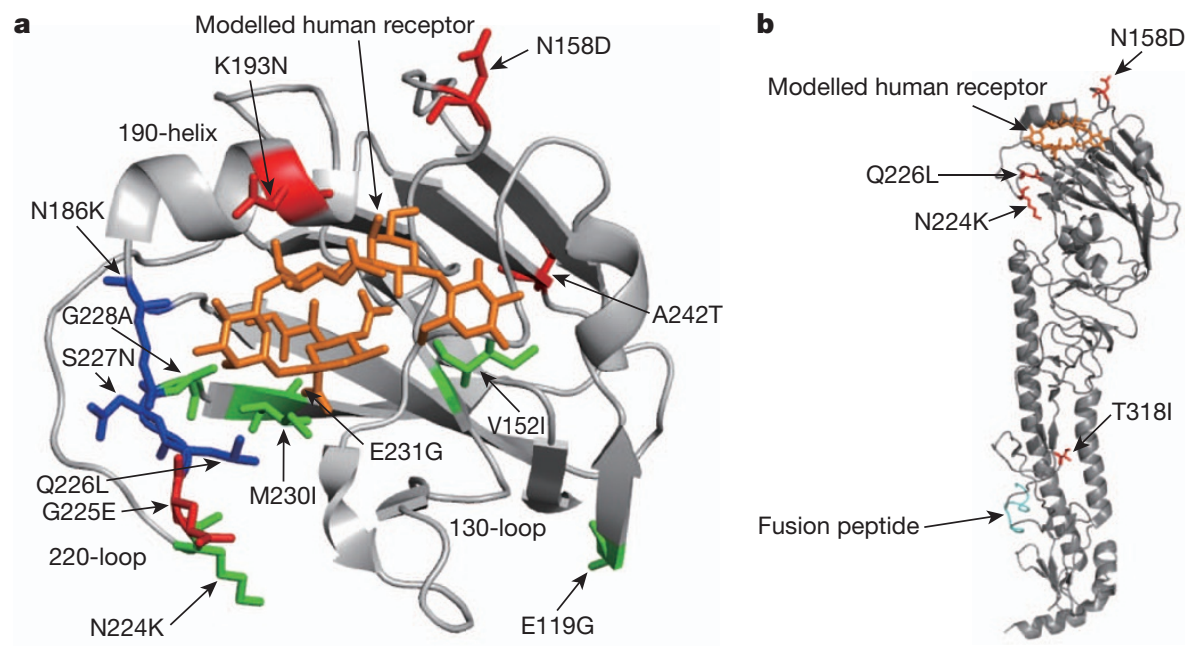

Figure $1 \mid$ Localization of amino acid changes identified in this study on the three-dimensional structure of the monomer of VN1203 HA (Protein Data Bank accession 2FK0) ${ }^{15}$. a, Close-up view of the globular head of VN1203 HA. Mutations known to increase affinity to human-type receptors are shown in blue. Amino acid changes not previously known to affect receptor binding are shown in green. Additional mutations that occurred in the HA of H5 avian-

human reassortant viruses during replication and/or transmission in ferrets are shown in red. b. The positions of four mutations in the HA of $\mathrm{H} 5$ transmissible reassortant mutant virus, $\mathrm{HA}(\mathrm{N} 158 \mathrm{D} / \mathrm{N} 224 \mathrm{~K} / \mathrm{Q} 226 \mathrm{~L} / \mathrm{T} 318 \mathrm{I}) / \mathrm{CA} 04$, are highlighted in red. The fusion peptide of HA is shown in cyan. All mutations are shown with $\mathrm{H} 3$ numbering. Images were created with MacPymol (http:// www.pymol.org/). 

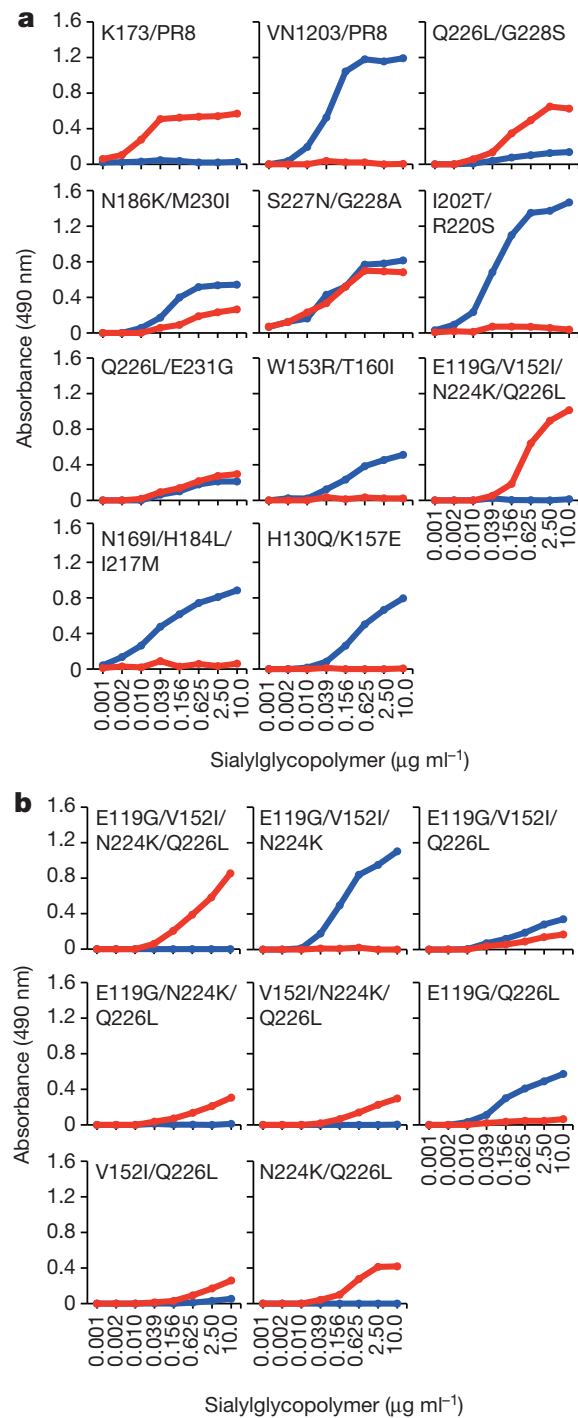

Figure $2 \mid$ Characterization of the receptor-binding properties of isolated viruses. a, Binding of VN1203 mutants to sialylglycopolymers in solid-phase binding assays. A human virus (K173/PR8), an avian virus (VN1203/PR8) and mutant VN1203/PR8 viruses were compared for their ability to bind to sialylglycopolymers containing either $\alpha 2,3$-linked (blue) or $\alpha 2,6$-linked (red) sialic acids. $\mathbf{b}$, Identification of mutations that confer binding to human-type receptors. c, Binding of VN1203 mutant viruses to human respiratory tissues. K173/PR8, VN1203/PR8 and mutant VN1203/PR8 viruses were incubated

To assess the effect of enhanced $\alpha 2,6$-glycan recognition on the attachment of viruses to human respiratory tracts, sections of tracheal and lung tissues were exposed to K173/PR8 (human-type receptor binder), VN1203/PR8 (avian-type receptor binder) and mutant VN1203/PR8 viruses (Fig. 2c). Because the N186K/M230I, S227N/ G228A, Q226L/E231G, E119G/V152I/N224K/Q226L and N224K/ Q226L mutants exhibited appreciable binding to Sia 2 2,6Gal (Fig. 2a, b), the attachment of these mutants was also tested. On tracheal sections, the K173/PR8 virus bound extensively to ciliated epithelial cells (Fig. 2c and Supplementary Fig. 3), whereas the VN1203/PR8 virus bound poorly. By contrast, on lung sections, both viruses bound extensively to the alveolar epithelial surface (both type I and II pneumocytes; Fig. 2c and Supplementary Fig. 4). The binding patterns of these viruses correlate with the distribution of Sia $\alpha 2,3 \mathrm{Gal}$ (that is, avian-type receptors; present in lung epithelia) and Sia $\alpha 2,6 \mathrm{Gal}$ (that is, human-type receptors; present in both trachea and lung epithelia) on the tissues, as observed with lectin staining ${ }^{18}$ (Supplementary Fig. 5). Like the human K173/PR8 virus, the E119G/V152I/N224K/Q226L and N224K/Q226L with human tissue sections and then stained with either anti-K173 antiserum (green) or anti-VN1203 HA antibodies (green). All sections were subsequently incubated with labelled secondary antibodies and Hoechst dye (blue). d, Characterization of the receptor-binding properties of N158D/N224K/ Q226L, N158D/N224K/Q226L/T318I and T318I viruses. The direct binding of virus to sialylglycopolymers containing either $\alpha 2,3$-linked (blue) or $\alpha 2,6$-linked (red) sialic acids was determined as described in panel a.

mutants exhibited strong binding to the ciliated epithelial cells of the trachea (Fig. 2c and Supplementary Fig. 3). By contrast, the N186K/ M230I, S227N/G228A and Q226L/E231G mutants displayed little-tono binding to tracheal epithelia (Fig. 2c), despite their binding to Sia $22,6 \mathrm{Gal}$ (Fig. 2a). A number of sialylated oligosaccharides with differing branching patterns and chain lengths are thought to be present on the cell surface ${ }^{19}$. We therefore speculate that the mutants can recognize a short glycan structure such as Sia $2,6 \mathrm{Gal} \beta 1,4 \mathrm{GlcNAc}$, but may not recognize longer, more complex glycan structures, which are possibly required for binding to human tracheal epithelium. On the other hand, all mutants bound to alveolar epithelial cells (both type I and II pneumocytes; Fig. $2 c$ and Supplementary Fig. 4). When the tissue sections were pre-treated with Arthrobacter ureafaciens sialidase (which cleaves all non-reducing terminally branched and unbranched sialic acids), virus binding to the tissues was substantially reduced (Supplementary Fig. 6a-c), confirming the sialic acid binding specificity of the virus. These data indicate that alterations in the receptor specificity of the E119G/V152I/N224K/Q226L and N224K/Q226L 
mutants have profound effects on virus attachment to human respiratory epithelium.

In an avian $\mathrm{H} 3 \mathrm{HA}$, the Q226L mutation changed the binding preference from avian- to human-type ${ }^{20}$. A previous study found that the Q226L mutation on an H5 HA does not confer efficient binding to $\alpha 2,6$-glycans in a glycan array ${ }^{15}$; however, when tested in combination with G228S, increased binding to human-type receptors, but not a complete switch from avian- to human-type receptor-binding specificity, was observed ${ }^{15}$. By contrast, here we found that Q226L in combination with $\mathrm{N} 224 \mathrm{~K}$ resulted in a switch from Sia $2,3 \mathrm{Gal}$ to Sia 2 2,6 Gal binding in an $\mathrm{H} 5 \mathrm{HA}$ and allowed virus binding to human tracheal epithelia (Fig. 2c). The receptor-binding domain of HA is formed by the 190-helix at the top of HA, the 220-loop at the edge of the globular head, and the 130-loop at the other edge of the globular head (Fig. 1a). Crystal structure analysis revealed that the 220-loop of avian $\mathrm{H} 5 \mathrm{HA}$ is closer to the opposing 130-loop than in human $\mathrm{H} 3 \mathrm{HA}$, indicating that a wider binding site for human $\mathrm{H} 3 \mathrm{HA}$, compared to that of avian $\mathrm{H} 5 \mathrm{HA}$, may be required to optimize contacts with the larger Sia $\alpha 2,6$-glycans ${ }^{21}$. N224 lies on the turn leading into the 220loop, adjacent to position 226 (Fig. 1a). Replacement of N224 may alter the orientation of the 220-loop and thus optimize contacts between L226 and Sia $2,6 \mathrm{Gal}$-containing receptors, thereby increasing the preference for $\alpha 2,6$ linkages.

Recent studies reported that 2009 pandemic H1N1 and H5N1 viruses show high genetic compatibility ${ }^{22,23}$. These two viruses have been isolated from pigs $^{24-28}$, which have been considered as 'mixing vessels' for the reassortment of avian, swine and human strains. Thus, the coexistence of $\mathrm{H} 5 \mathrm{~N} 1$ and 2009 pandemic H1N1 viruses could provide an opportunity for the generation of transmissible $\mathrm{H} 5$ avianhuman reassortants in mammals. Therefore, we generated reassortant viruses possessing the mutant VN1203 HAs generated above, and the seven remaining gene segments from a prototype 2009 pandemic H1N1 virus (A/California/04/2009, CA04). Experiments with viruses possessing the wild-type HA cleavage site were performed in enhanced biosafety level 3 (BSL3+) containment laboratories approved for such use by the Centers for Disease Control and Prevention (CDC) and the United States Department of Agriculture (USDA). Because efficient human-to-human transmission is a critical feature of pandemic influenza viruses, we examined the growth and transmissibility of reassortant viruses in ferrets, which are widely accepted as an animal model for influenza virus transmissibility and pathogenesis studies. Because the E119G/V152I/N224K/Q226L and N224K/Q226L variants bound extensively to human tracheal epithelia (Fig. 2c), we generated by reverse genetics ( $\mathrm{rg}$ ) three $\mathrm{H} 5$ reassortant viruses possessing the VN1203 HA or mutant HAs (all with the wild-type multibasic cleavage site) and the remaining genes from the CA04 virus. The VN1203 HA mutants tested included the one containing four mutations, E119G, V152I, N224K and Q226L (designated rg(E119G/V152I/N224K/ Q226L)/CA04), and another containing two mutations, N224K and Q226L (designated rg(N224K/Q226L)/CA04).

To determine whether the introduced HA mutations affected the replication of the $\mathrm{H} 5$ reassortant viruses, six ferrets were inoculated intranasally with $10^{6}$ plaque-forming units (p.f.u.) of virus. On day 3 after infection, a recombinant virus whose genes all came from CA04, rgCA04, replicated efficiently in the respiratory organs of infected animals, and was isolated from the colon, but not from any other organs tested (Fig. 3 and Supplementary Table 2). A virus possessing H5 VN1203 HA and the remaining genes from CA04 (designated rgVN1203/CA04) replicated to titres comparable to those of rgCA04 in nasal turbinates, but substantially less in the lungs. By contrast, the two H5 reassortant viruses with HA mutations (rg(E119G/V152I/ N224K/Q226L)/CA04 and $\mathrm{rg}(\mathrm{N} 224 \mathrm{~K} / \mathrm{Q} 226 \mathrm{~L}) / \mathrm{CA04})$ were severely limited in their replicative ability in trachea. Although virus titres in nasal turbinates and lung were not statistically different between $\operatorname{rg}(\mathrm{N} 224 \mathrm{~K} / \mathrm{Q} 226 \mathrm{~L}) / \mathrm{CA} 04$ and rgCA04, the virus titre in nasal turbinates was significantly lower in animals inoculated with rg(E119G/
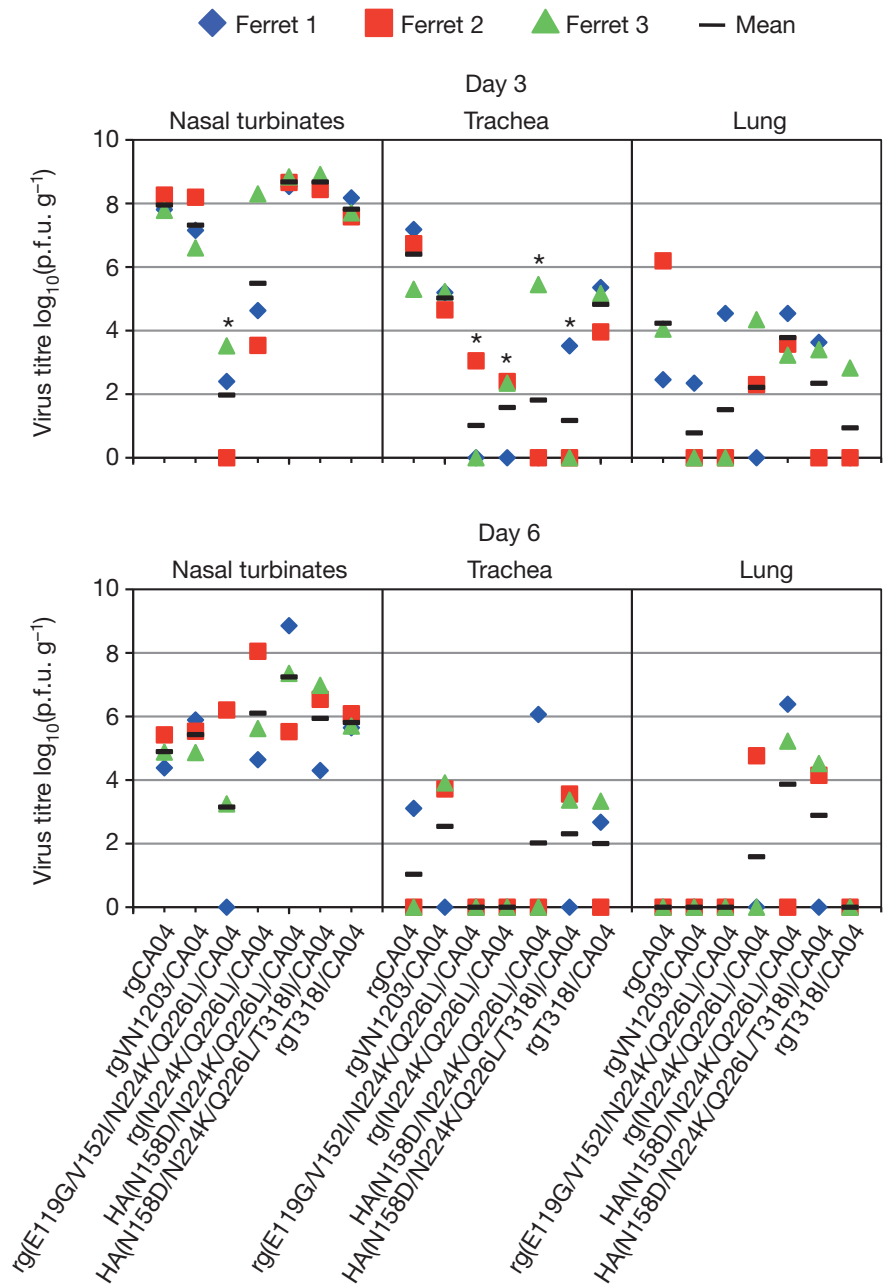

Figure 3 Virus replication in respiratory organs. Ferrets were infected intranasally with $10^{6}$ p.f.u. of virus. Three ferrets per group were killed on days 3 and 6 after infection for virus titration. Virus titres in nasal turbinates, trachea and lung were determined by use of a plaque assay on MDCK cells. Horizontal bars show the mean. Asterisks indicate virus titres significantly different from that of rgCA04 (Dunnett's test; $P<0.05$ ).

V152I/N224K/Q226L)/CA04 than in animals inoculated with rgCA04 (Dunnett's test; $P=0.0002$; Fig. 3). Notably, rgVN1203/CA04 (aviantype receptor binder) replicated efficiently in nasal turbinates of ferrets, which have a similar sialic acid receptor distribution pattern to that of the human respiratory $\operatorname{tract}^{29,30}$. The reason for this discrepancy is unclear; however, replication of avian $\mathrm{H} 5 \mathrm{~N} 1$ viruses in ferret nasal turbinates has been reported ${ }^{12,13}$.

Although virus titres in respiratory organs were generally lower on day 6 after infection than on day 3 after infection, $\operatorname{rg}(\mathrm{N} 224 \mathrm{~K} / \mathrm{Q} 226 \mathrm{~L}) /$ CA04 still showed high levels of replication at day 6 after infection; titres in nasal turbinates ranged from $10^{4.6}$ to $10^{8.1}$ p.f.u. $g^{-1}$ (Fig. 3). Sequence analysis of viruses in nasal turbinates on day 6 after infection revealed that viruses in ferret 2 and ferret 3 possessed N158D and $\mathrm{N} 158 \mathrm{~K}$ mutations in their HA (in addition to the original two mutations), respectively, leading to the loss of the glycosylation site at position 158 (that is, $158 \mathrm{~N}-\mathrm{S}-\mathrm{T}$ to $158 \mathrm{D}-\mathrm{S}-\mathrm{T}$ or $158 \mathrm{~K}-\mathrm{S}-\mathrm{T}$; Fig. 1a and Supplementary Table 3). In nasal turbinates on day 6 after infection, the titre of the virus with the N158D/N224K/Q226L mutations ( $10^{8.1}$ p.f.u. ${ }^{-1}$; see Fig. 3, ferret 2 of $\left.\mathrm{rg}(\mathrm{N} 224 \mathrm{~K} / \mathrm{Q} 226 \mathrm{~L}) / \mathrm{CA} 04\right)$ was approximately four orders of magnitude higher than that of the original $\mathrm{rg}(\mathrm{N} 224 \mathrm{~K} / \mathrm{Q} 226 \mathrm{~L}) / \mathrm{CA} 04$ ( $10^{4.6}$ p.f.u. ${ }^{-1}$; Fig. 3, ferret 1 of $\mathrm{rg}(\mathrm{N} 224 \mathrm{~K} / \mathrm{Q} 226 \mathrm{~L}) / \mathrm{CA} 04)$, whereas the virus with the N158K/ N224K/Q226L mutations $\left(10^{5.6}\right.$ p.f.u. ${ }^{-1}$; Fig. 3 , ferret 3 of $\operatorname{rg}(\mathrm{N} 224 \mathrm{~K} / \mathrm{Q} 226 \mathrm{~L}) / \mathrm{CA04})$ grew to one order of magnitude higher than 
the original mutant. These data indicate that the additional mutation N158D improved the replication of $\mathrm{rg}(\mathrm{N} 224 \mathrm{~K} / \mathrm{Q} 226 \mathrm{~L}) / \mathrm{CA} 04$ in ferrets. To test the effect of this mutation on the replication of $\mathrm{H} 5$ reassortant viruses in ferrets, we examined the replicative ability of a virus with the triple N158D/N224K/Q226L HA substitutions in ferrets. This HA(N158D/N224K/Q226L)/CA04 virus replicated efficiently in infected animals, except in the trachea (Fig. 3 and Supplementary Table 2). On day 3 after infection, this virus was isolated from the brain of two of the three animals tested, although we did not observe neurological signs in these animals. These results indicate that the N158D mutation contributed to the efficient growth in the nasal turbinates of ferrets of an H5 reassortant virus with the N224K/Q226L mutations. Removal of the glycosylation site at position 158 has been reported to result in enhanced binding of $\mathrm{H} 5 \mathrm{~N} 1$ viruses to human-type receptors in combination with the Q226L/G228S mutations ${ }^{7}$. A previous study showed that $\mathrm{H} 5 \mathrm{~N} 1$ viruses lacking this glycosylation site transmit efficiently by direct contact among guinea-pigs ${ }^{31}$. By contrast, H5N1 viruses that acquire this glycosylation site lose the ability to transmit among guinea-pigs. Therefore, we speculated that the loss of the glycosylation site in HA(N158D/N224K/Q226L)/CA04 virus may affect its transmissibility in ferrets.

To assess the ability of $\mathrm{H} 5$ reassortant viruses with human-type receptor specificity to transmit between ferrets, we placed naive ferrets in wireframe cages next to ferrets inoculated with $10^{6}$ p.f.u. of rgCA04, rgVN1203/CA04, rg(N224K/Q226L)/CA04, or HA(N158D/N224K/ Q226L)/CA04 (Supplementary Fig. 7). Similar to previous experiments ${ }^{32}$, rgCA04 was efficiently transmitted via respiratory droplets to all three contact ferrets, as evidenced by the detection of virus in nasal washes and haemagglutination inhibition (HI) antibody in these animals (Table 1 and Fig. 4). By contrast, rgVN1203/CA04 and $\mathrm{rg}(\mathrm{N} 224 \mathrm{~K} / \mathrm{Q} 226 \mathrm{~L}) / \mathrm{CA} 04$ were not transmitted; neither virus shedding nor seroconversion was detected in any contact animals, despite the binding of the latter to Sia $\alpha 2,6 \mathrm{Gal}$. This result was consistent with that of previous studies in which human-type receptor recognition was shown to be necessary but not sufficient for respiratory droplet transmission of an $\mathrm{H} 5 \mathrm{~N} 1$ virus in a ferret model $^{12,14}$. In the HA(N158D/ N224K/Q226L)/CA04-inoculated group, virus was recovered from two of the six contact ferrets (pairs 1 and 2) between days 5 and 7 after contact. Moreover, seroconversion was detected in five animals including those from which virus was recovered. No animals died in the course of these transmission experiments. This finding demonstrates the generation of an $\mathrm{H} 5 \mathrm{HA}$ that supports virus transmission by respiratory droplets among ferrets.

To determine whether additional mutations occurred in the HA of HA(N158D/N224K/Q226L)/CA04 during transmission, viral RNA was analysed from nasal washes of inoculated and contact ferrets (Fig. 4 and Supplementary Table 4). On day 5 after infection, the A242S and T318I mutations in HA were present in five (pairs 1, 3, 4, 5 and 6) and one (pair 2) of the six inoculated animals, respectively. Viruses derived from the contact animals of pair 1 on day 7 after contact had two changes in HA
(K193N and A242S) (Fig. 1a), whereas those derived from the contact animals of pair 2 contained a single change in HA (T318I) (Fig. 1b), indicating that additional changes in HA occurred during the infection of ferrets with HA(N158D/N224K/Q226L)/CA04. No mutations in the remaining genes were detected in any of these viruses from nasal washes compared with the CA04 virus sequences.

Because HA(N158D/N224K/Q226L)/CA04 was isolated from only one-third of the contact animals, we isolated a virus from the nasal wash of the contact ferret that shed a high titre $\left(10^{7.5}\right.$ p.f.u. $\left.\mathrm{ml}^{-1}\right)$ of virus on day 7 after contact (pair 2) (Fig. 4d) to evaluate the replication and transmissibility of that virus in ferrets. This mutant virus, designated HA(N158D/N224K/Q226L/T318I)/CA04, replicated efficiently in the nasal turbinates and was isolated from brain tissue (Fig. 3 and Supplementary Table 2). In the transmission study, four of the six contact ferrets were positive for virus between days 3 and 7 after contact, and all contact animals were seropositive; no animals died in the course of the transmission experiments (Table 1; Fig. 4e and Supplementary Fig. 8). Notably, this transmission pattern is comparable to that of the 1918 pandemic $H 1 N 1$ virus when tested under the same experimental conditions; the 1918 pandemic virus was recovered from the nasal wash of two of three contact animals (our own unpublished data). Sequence comparison of viruses from inoculated and contact animals identified mutations at positions 225 and 242 as well as a reversion at position 224 (Fig. 1a and Supplementary Table 5) (in addition to the original four mutations) although the 224 reversion was found only in viruses from inoculated ferrets. Collectively, these findings demonstrate that four amino acid substitutions (N158D/N224K/ Q226L/T318I) in H5 HA confer efficient respiratory droplet transmission in ferrets to a virus possessing an H5 HA in a 2009 pandemic H1N1 backbone. We also confirmed that recombinant viruses possessing the three HA mutations N158D, N224K and Q226L, or the four HA mutations N158D, N224K, Q226L and T318I, and the NA of VN1203 in a PR8 backgrand (designated N158D/N224K/Q226L or N158D/N224K/Q226L/T318I, respectively) preferentially bind to Sia 2,6Gal and attach to human tracheal epithelia (Fig. 2c, d).

HA(N158D/N224K/Q226L/T318I)/CA04 transmitted by respiratory droplet more efficiently than HA(N158D/N224K/Q226L)/ CA04, raising the possibility that the T318I mutation is involved in the efficient transmission of avian $\mathrm{H} 5 \mathrm{~N} 1$ /pandemic $\mathrm{H} 1 \mathrm{~N} 1$ reassortants. To explore the functional role of this mutation in respiratory droplet transmission, we generated an $\mathrm{H} 5$ reassortant expressing the H5 HA with the T318I mutation and examined its receptor-binding specificity and transmissibility. This reassortant (designated rgT318I/ CA04) bound to only Sia 2,3Gal and showed little binding to human tracheal epithelia (Fig. 2c, d). rgT318I/CA04 did not transmit via respiratory droplet among ferrets (Table 1 and Fig. 4f), although it replicated in nasal turbinates and trachea as efficiently as rgCA04 (Fig. 3 and Supplementary Table 2). These results indicate that the T318I mutation alone is not sufficient for $\mathrm{H} 5$ reassortant viruses to transmit efficiently among ferrets.

Table 1 | Transmission in ferrets inoculated with $\mathrm{H} 5$ avian-human reassortant viruses

\begin{tabular}{|c|c|c|c|c|c|}
\hline \multirow[t]{2}{*}{ Virus } & \multicolumn{3}{|c|}{ Inoculated ferrets } & \multicolumn{2}{|r|}{ Contact ferrets } \\
\hline & $\begin{array}{l}\text { Weight loss } \\
(\%)^{*}\end{array}$ & $\begin{array}{l}\text { Peak virus titre in nasal wash } \\
\left.\text { (mean } \log _{10} \text { (p.f.u. } \mathrm{ml}^{-1}\right) \text { ) } \\
\text { (days after inoculation) }\end{array}$ & $\begin{array}{c}\text { Seroconversion } \\
\text { (positive and total numbers) } \\
\text { (HI titre) }{ }^{\dagger}\end{array}$ & $\begin{array}{l}\text { Virus detection in } \\
\text { nasal wash (positive } \\
\text { and total numbers) }\end{array}$ & $\begin{array}{c}\text { Seroconversion } \\
\text { (positive and total numbers) } \\
\text { (HI titre) }\end{array}$ \\
\hline$\overline{\mathrm{rgCAO4}}$ & 3 of $3(15.1)$ & $7.5(1)$ & 3 of $3(\geq 1,280, \geq 1,280, \geq 1,280)$ & 3 of 3 & 3 of $3(\geq 1,280, \geq 1,280, \geq 1,280)$ \\
\hline rgVN1203/CA04 & 3 of $3(5.9)$ & $5.3(5)$ & 3 of $3(80,40,80)$ & 0 of 3 & 0 of $3(<10,<10,<10)$ \\
\hline $\mathrm{rg}(\mathrm{N} 224 \mathrm{~K} / \mathrm{Q} 226 \mathrm{~L}) / \mathrm{CA04}$ & 2 of $3(7.8)$ & $3.9(5)$ & 3 of $3(\geq 1,280, \geq 1,280, \geq 1,280)$ & 0 of 3 & 0 of $3(<10,<10,<10)$ \\
\hline $\begin{array}{l}\text { HA(N158D/N224K/Q226L)/ } \\
\text { CA04 }\end{array}$ & 6 of $6(5.7)$ & $6.7(3)$ & $\begin{array}{c}6 \text { of } 6(640, \geq 1,280, \geq 1,280,640 \\
\quad \geq 1,280, \geq 1,280)\end{array}$ & 2 of 6 & 5 of $6(160,320,20,160,40,<10)$ \\
\hline $\begin{array}{l}\text { HA(N158D/N224K/Q226L/ } \\
\text { T318I)/CA04 }\end{array}$ & 6 of $6(9.8)$ & $6.1(5)$ & $\begin{array}{c}6 \text { of } 6(\geq 1,280, \geq 1,280,640, \geq 1,280, \\
\geq 1,280, \geq 1,280)\end{array}$ & 4 of 6 & $\begin{array}{c}6 \text { of } 6(640,640, \geq 1280,80 \\
\geq 1,280,320)\end{array}$ \\
\hline rgT318I/CA04 & 3 of $5(1.5) \S$ & $5.6(3)$ & 5 of $5(40,20,20,40,40)$ & 0 of 5 & 0 of $5(<10,<10,<10,<10,<10)$ \\
\hline
\end{tabular}

\footnotetext{
* Maximum percentage weight loss is shown.
}

† Haemagglutination inhibition (HI) assays were carried out with homologous virus and turkey red blood cells.

$\$$ One animal did not lose any body weight.

$\S$ Two animals did not lose any body weight. 


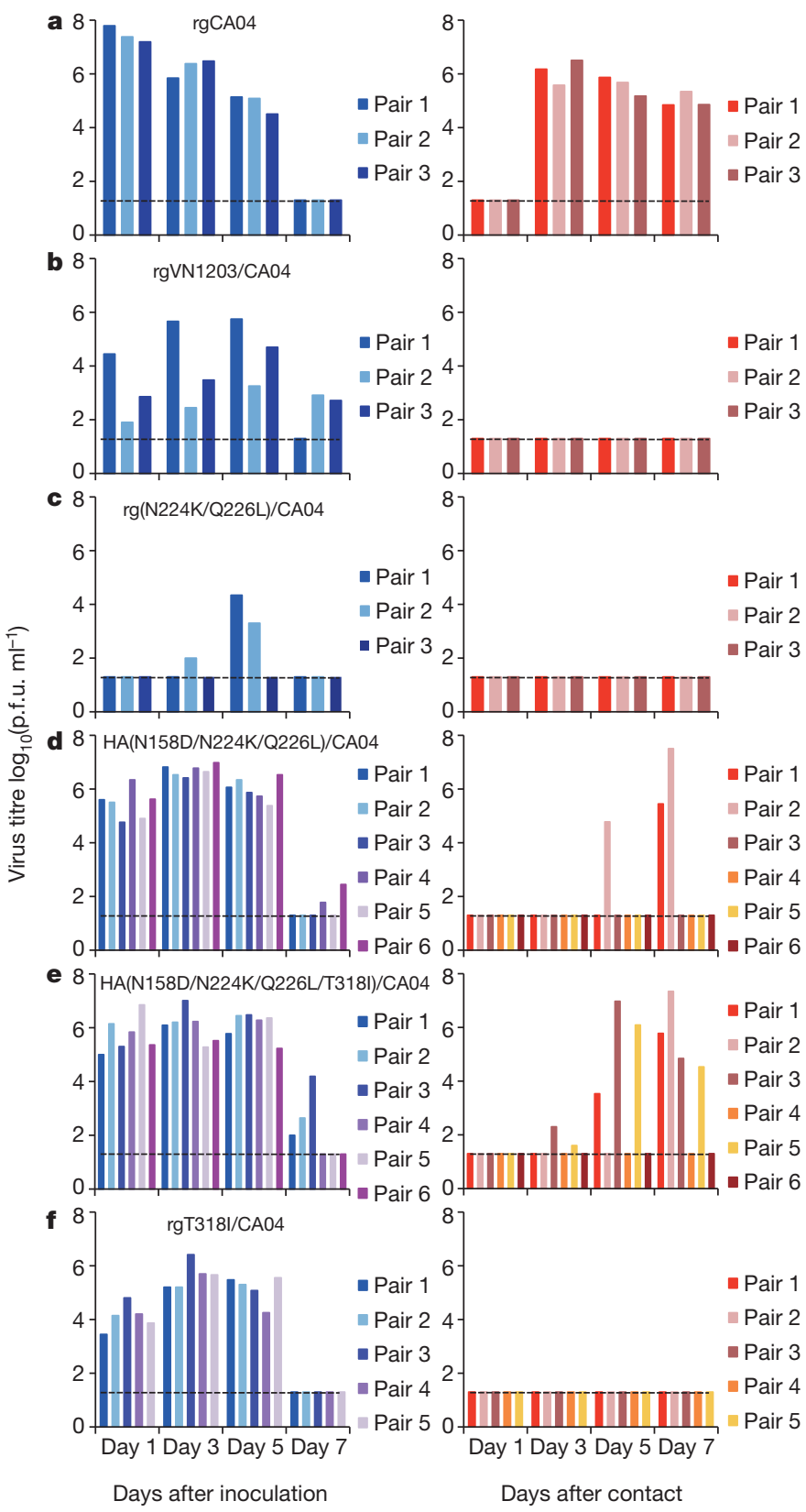

Figure $4 \mid$ Respiratory droplet transmission of H5 avian-human reassortant viruses in ferrets. a-f, Groups of three, five, or six ferrets were inoculated intranasally with $10^{6}$ p.f.u. of rgCA04 (a), rgVN1203/CA04 (b), $\operatorname{rg}(\mathrm{N} 224 \mathrm{~K} / \mathrm{Q} 226 \mathrm{~L}) / \mathrm{CA} 04$ (c), HA(N158D/N224K/Q226L)/CA04 (d), HA(N158D/N224K/Q226L/T318I)/CA04 (e), or rgT318I/CA04 (f). One day after infection, three, five, or six naive ferrets were placed in adjacent cages. Nasal washes were collected every other day from both inoculated (left panel) and contact (right panel) animals for virus titration. Virus titres in organs were determined by using a plaque assay on MDCK cells. The lower limit of detection is indicated by the horizontal dashed line.

Influenza virus HA protein has membrane-fusion as well as receptorbinding activity. Notably, in the three-dimensional model of influenza A virus HA, residue 318 is located proximally to the fusion peptide (Fig. 1b), which has key roles in the membrane fusion process. To assess the effect of HA mutations on low-pH-induced membrane fusion activity, we examined the $\mathrm{pH}$ at which the fusion activity of wild-type and mutant HA was activated (Fig. 5). The wild-type HA had a threshold for membrane fusion of $\mathrm{pH}$ 5.7; the N224K/Q226L and N158D/N224K/Q226L mutations raised the threshold for fusion to $>$ pH 5.9, whereas the T318I mutation reduced the threshold for fusion to $\mathrm{pH}$ 5.5. The N158D/N224K/Q226L/T318I mutations showed a

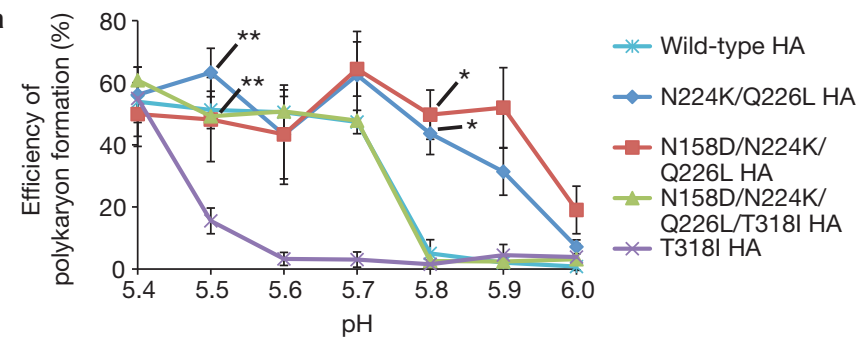

b

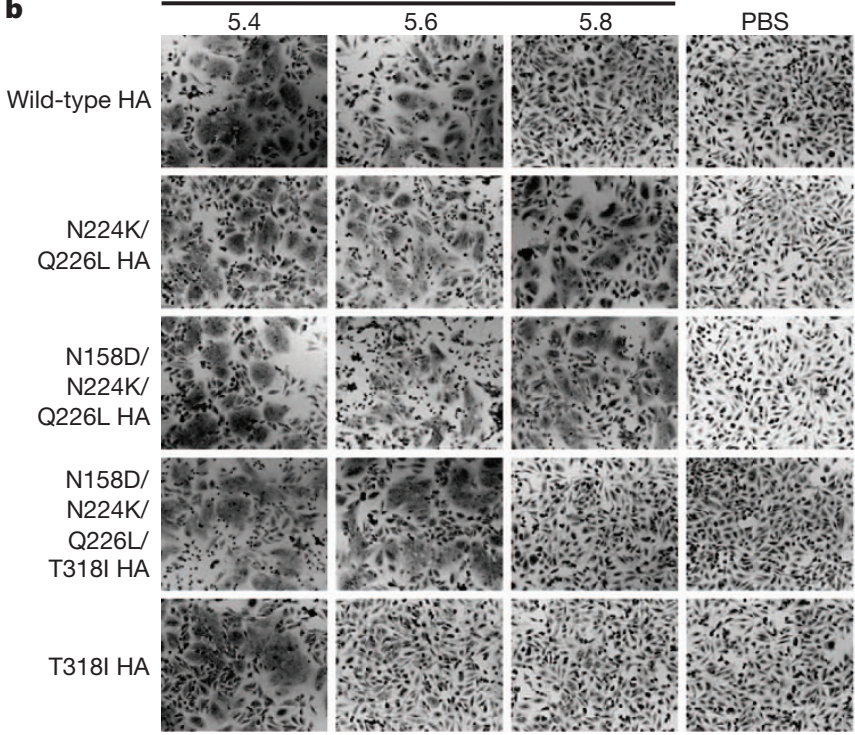

Figure 5 Polykaryon formation by HeLa cells expressing wild-type or mutant HAs after acidification at low $\mathrm{pH}$. a, The efficiency of polykaryon formation over a $\mathrm{pH}$ range of 5.4-6.0 was estimated from the number of nuclei in polykaryons divided by the total number of nuclei in the same field. The mean and standard deviations determined from five randomly chosen fields of cell culture are shown. Single asterisks indicate values significantly different between the wild-type HA and the N224K/Q226L or N158D/N224K/Q226L HA (Tukey test; $P<0.05$ ). The double asterisk indicates values significantly different between the T318I HA and the N224K/Q226L or N158D/N224K/ Q226L HA (Tukey test; $P<0.05$ ). b, Representative fields of cells expressing the indicated HAs and exposed to $\mathrm{pH} 5.4,5.6$, or 5.8 are shown. Images were taken at $\times 10$ magnification.

wild-type fusogenic properties (that is, a threshold at $\mathrm{pH}$ 5.7). The HA of influenza virus undergoes a low-pH-dependent conformational change, which is required for fusion of the viral envelope with the target membrane ${ }^{33}$. Such a conformational change to a fusion-active form can also lead to viral inactivation. Therefore, sustained and efficient human-to-human transmission of virus may require a certain level of stability of the HA protein in an acidic environment, as the $\mathrm{pH}$ of human nasal mucosa, where human influenza viruses replicate primarily, is approximately $\mathrm{pH}$ 5.5-6.5 (ref. 34). Our findings suggest that an increase in the $\mathrm{pH}$ threshold for fusion as a result of the $\mathrm{N} 224 \mathrm{~K}$ / Q226L mutations that shift the HA receptor recognition from aviantype to human-type may reduce HA protein stability; however, the T318I mutation decreases the $\mathrm{pH}$ threshold for fusion activity, resulting in a stable mutant HA.

Because heat treatment at neutral $\mathrm{pH}$ is also known to promote a fusogenic form of HA protein ${ }^{35,36}$ and serve as a surrogate assay for HA stability $^{37}$, we next tested whether the HA mutations described above affect the heat stability of the HA protein. Wild-type and mutant HA viruses were incubated at $50{ }^{\circ} \mathrm{C}$ for various times, after which the loss of infectivity and haemagglutination activity were determined. The wild-type and N224K/Q226L viruses lost most of their infectivity by heating for $60 \mathrm{~min}\left(>5.5-\log _{10}\right.$ decrease in titre; Fig. $\left.6 \mathrm{a}\right)$, whereas the 
a

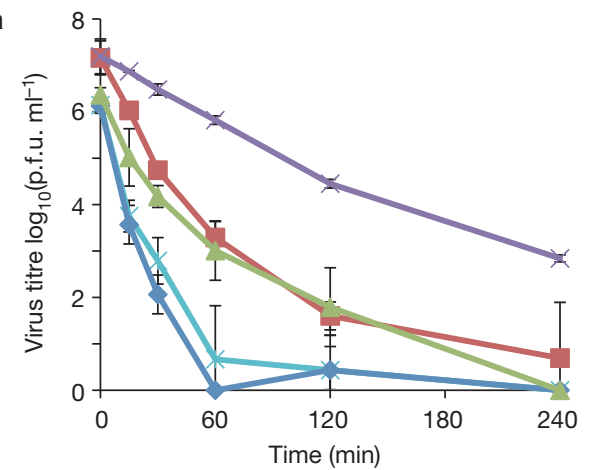

b

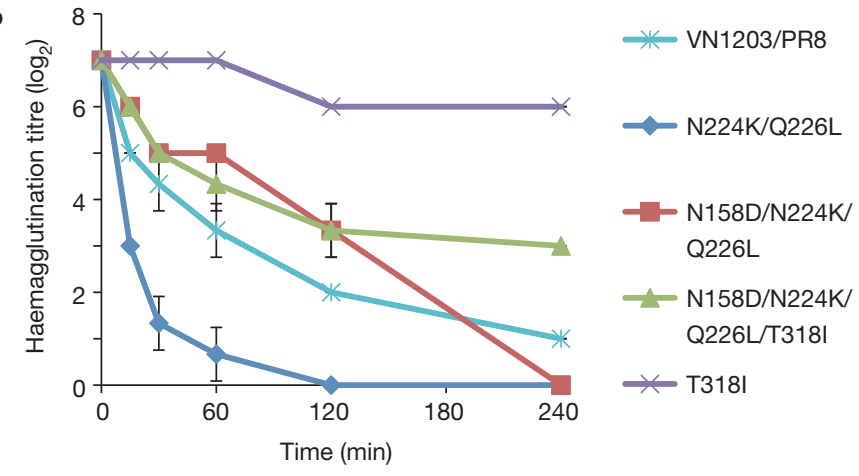

Figure $6 \mid$ Effect of heat treatment on the infectivity and haemagglutination activity of viruses. Aliquots of a virus stock containing $128 \mathrm{HA}$ units were incubated for the times indicated at $50{ }^{\circ} \mathrm{C}$. a, Virus titres in heat-treated samples were determined by plaque assays on MDCK cells. b, Haemagglutination titres in heat-treated samples were determined by using haemagglutination assays with $0.5 \%$ TRBCs. Each point represents the mean \pm standard deviation from triplicate experiments.
N158D/N224K/Q226L and N158D/N224K/Q226L/T318I mutants exhibited considerable tolerance to high temperature (3.9- and $3.4-\log _{10}$ decrease after a 60 -min incubation, respectively) and the T318I mutant was most resistant (only a $1.4-\log _{10}$ decrease under the same conditions). In haemagglutination assays, the N224K/ Q226L mutant HA lost activity more rapidly than did the wild-type $\mathrm{HA}$, and N158D/N224K/Q226L lost activity more rapidly than did the N158D/N224K/Q226L/T318I mutant (Fig. 6b). Thus, addition of the N158D mutation to the N224K/Q226L HA increased HA stability and subsequent addition of the fourth mutation, T318I, rendered the HA protein even more stable. Taken together, these results suggest that the addition of the T318I mutation to H5 HAs that preferentially recognize human-type receptors restores HA protein stability, thereby allowing a virus carrying the N158D/N224K/Q226L/T318I mutations in HA to transmit efficiently via respiratory droplet among ferrets. In conclusion, a fine balance of mutations affecting different functions in HA (such as receptor-binding specificity and HA stability) may be critical to confer transmissibility in ferrets.

We next compared the pathogenicity in ferrets of $\mathrm{H} 5$ avian-human reassortants with that of the pandemic H1N1 virus CA04 (Fig. 7, Supplementary Information and Supplementary Figs 9-11). The control virus, rgCA04, caused substantial body weight loss (15.1\%) (Table 1 and Supplementary Fig. 9). By contrast, the four reassortant viruses caused only modest weight loss $(<10 \%)$ in most of the animals. However, no statistically significant differences in body weight loss were found between the reassortant viruses and rgCA04. Pathological examination revealed similar histological changes and levels of viral antigens in the nasal mucosa of rgCA04-, HA(N158D/N224K/Q226L)/ CA04- and HA(N158D/N224K/Q226L/T318I)/CA04-infected ferrets (Fig. 7a, b). In the rgVN1203/CA04 and $\mathrm{rg}(\mathrm{N} 224 \mathrm{~K} / \mathrm{Q} 226 \mathrm{~L}) / \mathrm{CA} 04$ groups, however, less tissue damage was found in the nasal mucosa compared with the rgCA04 group on day 3 after infection (Dunnett's test; $P=0.0057$ and 0.0175 , respectively; Fig. $7 \mathrm{~b}$ ). In addition, all three a

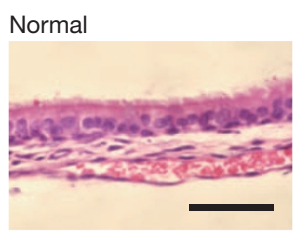

rgCA04

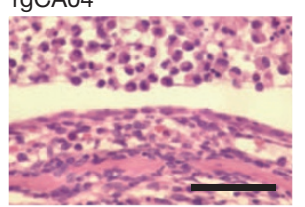

rgVN1203/CA04

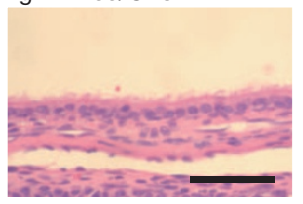

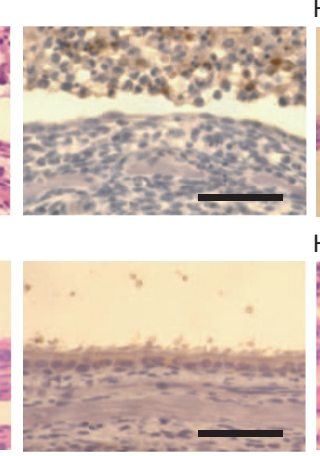

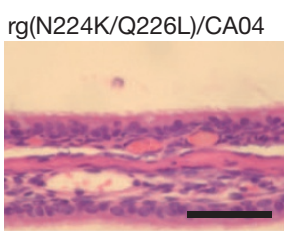

HA(N158D/N224K/Q226L)/CA04

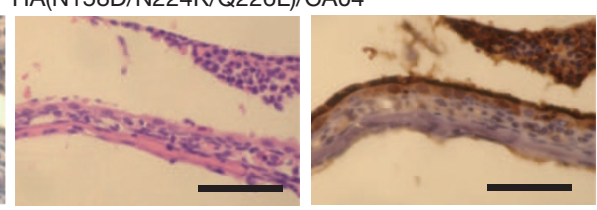

HA(N158D/N224K/Q226L/T318I)/CA04

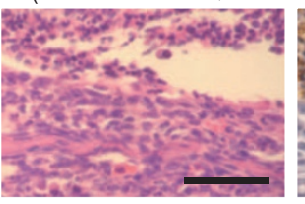

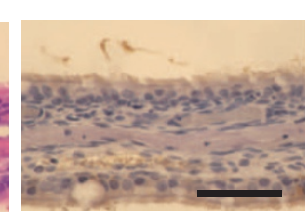

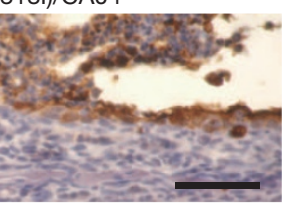

b

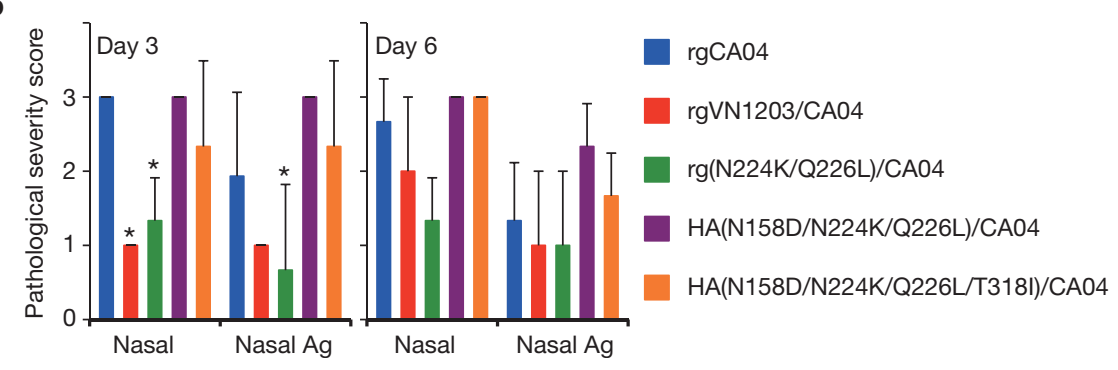

Figure 7 Pathological analyses of $\mathrm{H} 5$ avianhuman reassortant viruses. a, Representative histological changes in nasal turbinates from influenza-virus-infected ferrets. Three ferrets per group were infected intranasally with $10^{6}$ p.f.u. of virus, and tissues were collected on day 3 after infection for pathological examination. Uninfected ferret tissues served as negative controls (normal). Left panel, haematoxylin-and-eosin staining. Right panel, immunohistochemical staining for viral antigen detection (brown staining). Scale bars, $50 \mu \mathrm{m}$. b, Pathological severity scores in infected ferrets. To represent comprehensive histological changes, respiratory tissue slides were evaluated by scoring the pathological changes and viral antigen expression levels. The pathological scores were determined for each animal in each group $(n=3$ per group on days 3 and 6 after infection) using the following scoring system: 0 , no pathological change/antigen negative; 1 , affected area $(<30 \%)$ or only interstitial lesion/rare viral antigens; 2 , affected area $(<80 \%, \geq 30 \%) /$ moderate viral antigens; 3 , severe lesion $(\geq 80 \%) /$ many viral antigens. Nasal, pathological changes in the nasal mucosa; nasal Ag, viral antigens in the nasal mucosa. Asterisks indicate virus pathological scores significantly different from that of rgCA04 (Dunnett's test; $P<0.05$ ). Error bars denote standard deviation. 
viruses caused lung lesions (Supplementary Information and Supplementary Figs 10 and 11).

To assess whether current control measures may be effective against the $\mathrm{H} 5$ transmissible reassortant mutant virus, we examined the reactivity of sera from individuals vaccinated with an H5N1 prototype vaccine $^{38}$ against a virus possessing the N158D/N224K/Q226L/ T318I mutations in HA. We found that pooled human sera from individuals immunized with this vaccine reacted with the virus possessing the mutant H5 HA (N158D/N224K/Q226L/T318I) at a higher titre than with a wild-type H5 HA virus (VN1203/PR8; Supplementary Table 6), indicating that current $\mathrm{H} 5 \mathrm{~N} 1$ vaccines would be efficacious against the $\mathrm{H} 5$ transmissible reassortant mutant virus. In addition, the H5 transmissible reassortant mutant virus (HA(N158D/N224K/ Q226L/T318I)/CA04) was highly susceptible to a licensed NA inhibitor, oseltamivir (Supplementary Table 7). These experiments show that appropriate control measures would be available to combat the transmissible virus described in this study.

Currently, we do not know whether the mutations that we identified in this study that allowed the HA(N158D/N224K/Q226L/T318I)/ CA04 virus to be transmissible in ferrets would also support sustained human-to-human transmission. In particular, we wish to emphasize that the transmissible HA(N158D/N224K/Q226L/T318I)/CA04 virus possesses seven segments (all but the HA segment) from a human pandemic 2009 H1N1 virus. Human-virus-characteristic amino acids in these seven segments may have critically contributed to the respiratory droplet transmission of the HA(N158D/N224K/Q226L/T318I)/ CA04 virus in ferrets. Examples include amino acids in the PB2 polymerase protein that confer efficient replication in mammalian, but not avian, cells ${ }^{39-43}$. As the PB2 gene of the HA(N158D/N224K/ Q226L/T318I)/CA04 virus is of human virus origin, the virus possesses high replicative ability in mammalian cells. In contrast, most avian virus PB2 proteins lack these human-type amino acids, although one of these changes (a glutamic-acid-to-lysine mutation at position 627 ) is found in highly pathogenic avian H5N1 viruses circulating in the Middle East ${ }^{44}$. As a second example, the viral NA gene may contribute to viral transmissibility. The NA protein cleaves $\alpha$-ketosidic linkages between a terminal sialic acid and an adjacent sugar residue, an activity that balances the sialic-acid-binding activity of HA. A recent study found that a human virus NA gene was critical to confer limited transmissibility to a mutant $\mathrm{H} 5$ avian-human reassortant virus ${ }^{14}$. In general, a human-type receptor recognizing H5 HA alone may not be sufficient to confer transmissibility in mammals, but may have to act together with other human-virus-characteristic traits (in $\mathrm{PB} 2, \mathrm{NA}$, and/or other viral proteins). Therefore, at this point we cannot predict whether the four mutations in the H5 HA identified here would render a wholly avian $\mathrm{H} 5 \mathrm{~N} 1$ virus transmissible.

Three of the residues identified here (N224, Q226 and T318) have been strictly conserved among H5 HA proteins isolated since 2003. However, as $\mathrm{H} 5 \mathrm{~N} 1$ viruses continue to evolve and infect people, receptor-binding variants of $\mathrm{H} 5 \mathrm{~N} 1$ viruses, including avian-human reassortant viruses as tested here, may emerge. One of the four mutations we identified in our transmissible virus, the N158D mutation, results in loss of a glycosylation site. Many $\mathrm{H} 5 \mathrm{~N} 1$ viruses isolated in the Middle East, Africa, Asia and Europe do not have this glycosylation site. Therefore, only three nucleotide changes are needed for the HA of these viruses to support efficient transmission in ferrets. In addition, the $\mathrm{H} 5 \mathrm{~N} 1$ viruses circulating in these geographic areas also possess a glutamic-acid-to-lysine mutation at position 627 in the PB2 protein, which promotes viral replication in certain mammals, including humans ${ }^{40,45}$. Therefore, these viruses may be several steps closer to those capable of efficient transmission in humans and are of concern.

Our study highlights the pandemic potential of viruses possessing an $\mathrm{H} 5 \mathrm{HA}$. Although current vaccines may protect against a virus similar to that tested here, the continued evolution of $\mathrm{H} 5 \mathrm{~N} 1$ viruses reinforces the need to prepare and update candidate vaccines to $\mathrm{H} 5$ viruses. The amino acid changes identified here will help individuals conducting surveillance in regions with circulating $\mathrm{H} 5 \mathrm{~N} 1$ viruses (for example, Egypt, Indonesia, Vietnam) to recognize key residues that predict the pandemic potential of isolates. Rapid responses in a potential pandemic situation are essential in order to generate appropriate vaccines and initiate other public health measures to control infection. Furthermore, our findings are of critical importance to those making public health and policy decisions.

Our research answers a fundamental question in influenza research: can H5-HA-possessing viruses support transmission in mammals? Moreover, our findings have suggested that different mechanisms (that is, receptor-binding specificity and HA stability) may act in concert for efficient transmissibility in mammals. This knowledge will facilitate the identification of additional mutations that affect viral transmissibility; the monitoring of this expanded set of changes in natural isolates may improve our ability to assess the pandemic potential of $\mathrm{H} 5 \mathrm{~N} 1$ viruses. Thus, although a pandemic $\mathrm{H} 5 \mathrm{~N} 1$ virus may not possess the amino acid changes identified in our study, the findings described here will advance our understanding of the mechanisms and evolutionary pathways that contribute to avian influenza virus transmission in mammals.

\section{METHODS SUMMARY}

Viruses. All recombinant viruses were generated by using reverse genetics essentially as described previously ${ }^{16}$. All experiments with the viruses possessing the wildtype HA cleavage site were performed in an enhanced biosafety level 3 (BSL3+) containment laboratory approved for such use by the CDC and the USDA.

Infection and transmission in ferrets. Six-ten-month-old female ferrets (Triple F Farms) were intramuscularly anaesthetized and intranasally inoculated with $10^{6}$ p.f.u. $(500 \mu \mathrm{l})$ of virus. On days 3 and 6 after infection, ferrets were killed for virological and pathological examinations. The virus titres in various organs were determined by use of plaque assays in MDCK cells.

For transmission studies in ferrets, animals were housed in adjacent transmission cages that prevented direct and indirect contact between animals but allowed spread of influenza virus through the air (Showa Science; Supplementary Fig. 7). Ferrets were intranasally inoculated with $10^{6}$ p.f.u. $(500 \mu \mathrm{l})$ of virus (inoculated ferrets) Twenty-four hours after infection, naive ferrets were each placed in a cage adjacent to an inoculated ferret (contact ferrets). To assess viral replication in the nasal turbinates, we determined viral titres in nasal washes collected from virus-inoculated and contact ferrets on day 1 after inoculation or co-housing, respectively, and then every other day. Animal studies were performed in accordance with Animal Care and Use Committee guidelines of the University of Wisconsin-Madison.

Biosafety and biosecurity. All recombinant DNA protocols were approved by the University of Wisconsin-Madison's Institutional Biosafety Committee after risk assessments were conducted by the Office of Biological Safety, and by the University of Tokyo's Subcommittee on Living Modified Organisms, and, when required, by the competent minister of Japan. In addition, the University of Wisconsin-Madison Biosecurity Task Force regularly reviews the research program and ongoing activities of the laboratory. The task force has a diverse skill set and provides support in the areas of biosafety, facilities, compliance, security and health. Members of the Biosecurity Task Force are in frequent contact with the principal investigator and laboratory personnel to provide oversight and assure biosecurity. Experiments with viruses possessing the wild-type HA cleavage site were performed in enhanced BSL3 containment laboratories approved for such use by the CDC and the USDA. Ferret transmission studies were conducted by three scientists with both DVM and $\mathrm{PhD}$ degrees who each had more than minimum of 6 years of experience with highly pathogenic influenza viruses and animal studies with highly pathogenic viruses. Our staff wear powered air-purifying respirators that filter the air, and disposable coveralls; they shower out on exit from the facility. The containment facilities at University of Wisconsin-Madison were designed to exceed standards outlined in Biosafety in Microbiological and Biomedical Laboratories (5th edition; http://www.cdc.gov/biosafety/publications/ bmbl5/BMBL.pdf). Features of the BSL3-enhanced suites include entry/exit through a shower change room, effluent decontamination, negative air-pressure laboratories, double-door autoclaves, double HEPA-filtered exhaust air, and gas decontamination ports. The BSL3-Agriculture suite features include all those listed for BSL3-enhanced plus HEPA-filtered supply and double-HEPA-filtered exhaust air, double-gasketed watertight and airtight seals, airtight dampers on all ductwork, and the structure was pressure-decay tested during commissioning. The University of Wisconsin-Madison facility has a dedicated alarm system that monitors all building controls and sends alarms ( $\sim 500$ possible alerts). Redundancies and emergency resources are built-in to the facility including two 
air handlers, two compressors, two filters each place filters are needed, two effluent sterilization tanks, two power feeds to the building, an emergency generator in case of a power failure and other physical containment measures in the facility that operate without power. Biosecurity monitoring of the facility is ongoing. All personnel undergo Select Agent security risk assessment by the United States Criminal Justice Information Services Division and complete rigorous biosafety, BSL3 and Select Agent training before participating in BSL3-level experiments. Refresher training is scheduled on a regular basis. The principal investigator participates in training sessions and emphasizes compliance to maintain safe operations and a responsible research environment. The laboratory occupational health plan is in compliance with the University of Wisconsin-Madison Occupational Health Program. Select agent virus inventory is checked monthly and submitted to the University of Wisconsin-Madison Research Compliance Specialist. Virus inventory is submitted 1-2 times per year to the file holder in the Select Agent branch of the CDC. The research program, procedures, occupational health plan, documentation, security and facilities are reviewed annually by the University of Wisconsin-Madison Responsible Official and at regular intervals by the CDC and the Animal and Plant Health Inspection Service (APHIS) as part of the University of Wisconsin-Madison Select Agent Program.

Full Methods and any associated references are available in the online version of the paper at www.nature.com/nature.

\section{Received 18 August 2011; accepted 9 March 2012.} Published online 2 May 2012.

1. Glaser, L. etal. A single amino acid substitution in 1918 influenza virus hemagglutinin changes receptor binding specificity. J. Virol. 79, 11533-11536 (2005).

2. Matrosovich, M. etal. Early alterations of the receptor-binding properties of $\mathrm{H} 1, \mathrm{H} 2$, and $\mathrm{H} 3$ avian influenza virus hemagglutinins after their introduction into mammals. J. Virol. 74, 8502-8512 (2000)

3. Rogers, G. N. \& Paulson, J. C. Receptor determinants of human and animal influenza virus isolates: differences in receptor specificity of the $\mathrm{H} 3$ hemagglutinin based on species of origin. Virology 127, 361-373 (1983).

4. Auewarakul, P. et al. An avian influenza H5N1 virus that binds to a human-type receptor. J. Virol. 81, 9950-9955 (2007).

5. Gambaryan, A. et al. Evolution of the receptor binding phenotype of influenza A (H5) viruses. Virology 344, 432-438 (2006).

6. Stevens, J. et al. Recent avian H5N1 viruses exhibit increased propensity for acquiring human receptor specificity. J. Mol. Biol. 381, 1382-1394 (2008).

7. Wang, W. et al. Glycosylation at $158 \mathrm{~N}$ of the hemagglutinin protein and receptor binding specificity synergistically affect the antigenicity and immunogenicity of a live attenuated H5N1 A/Vietnam/1203/2004 vaccine virus in ferrets. J. Virol. 84, 6570-6577 (2010)

8. Watanabe, Y. et al. Acquisition of human-type receptor binding specificity by new H5N1 influenza virus sublineages during their emergence in birds in Egypt. PLoS Pathog. 7, e1002068 (2011).

9. Yamada, S. et al. Haemagglutinin mutations responsible for the binding of $\mathrm{H} 5 \mathrm{~N} 1$ influenza A viruses to human-type receptors. Nature 444, 378-382 (2006).

10. Jackson, S. et al. Reassortment between avian $\mathrm{H} 5 \mathrm{~N} 1$ and human $\mathrm{H} 3 \mathrm{~N} 2$ influenza viruses in ferrets: a public health risk assessment. J. Virol. 83, 8131-8140 (2009).

11. Maines, T. R. et al. Lack of transmission of $\mathrm{H} 5 \mathrm{~N} 1$ avian-human reassortant influenza viruses in a ferret model. Proc. Natl Acad. Sci. USA 103, 12121-12126 (2006).

12. Maines, T. R. et al. Effect of receptor binding domain mutations on receptor binding and transmissibility of avian influenza H5N1 viruses. Virology 413, 139-147 (2011).

13. Yen, H. L. etal. Inefficient transmission of $\mathrm{H} 5 \mathrm{~N} 1$ influenza viruses in a ferret contact model. J. Virol. 81, 6890-6898 (2007).

14. Chen, L. M. et al. In vitro evolution of H5N1 avian influenza virus toward humantype receptor specificity. Virology 422, 105-113 (2012).

15. Stevens, J. et al. Structure and receptor specificity of the hemagglutinin from an H5N1 influenza virus. Science 312, 404-410 (2006).

16. Neumann, G. et al. Generation of influenza A viruses entirely from cloned cDNAs. Proc. Natl Acad. Sci. USA 96, 9345-9350 (1999).

17. Hatakeyama, S. et al. Enhanced expression of an $\alpha 2,6$-linked sialic acid on MDCK cells improves isolation of human influenza viruses and evaluation of their sensitivity to a neuraminidase inhibitor. J. Clin. Microbiol. 43, 4139-4146 (2005),

18. Shinya, K. et al. Avian flu: influenza virus receptors in the human airway. Nature 440, 435-436 (2006)

19. Varki, A. Glycan-based interactions involving vertebrate sialic-acid-recognizing proteins. Nature 446, 1023-1029 (2007).

20. Rogers, G. N. et al. Host-mediated selection of influenza virus receptor variants. Sialic acid- $\alpha 2,6 \mathrm{Gal}$-specific clones of A/duck/Ukraine/1/63 revert to sialic acida2,3Gal-specific wild type in ovo. J. Biol. Chem. 260, 7362-7367 (1985).

21. Ha, Y., Stevens, D. J., Skehel, J. J. \& Wiley, D. C. X-ray structures of H5 avian and H9 swine influenza virus hemagglutinins bound to avian and human receptor analogs. Proc. Natl Acad. Sci. USA 98, 11181-11186 (2001).

22. Cline, T. D. et al. Increased pathogenicity of a reassortant 2009 pandemic H1N1 influenza virus containing an H5N1 hemagglutinin. J. Virol. 85, 12262-12270 (2011).
23. Octaviani, C. P., Ozawa, M., Yamada, S., Goto, H. \& Kawaoka, Y. High level of genetic compatibility between swine-origin $\mathrm{H} 1 \mathrm{~N} 1$ and highly pathogenic avian $\mathrm{H} 5 \mathrm{~N} 1$ influenza viruses. J. Virol. 84, 10918-10922 (2010).

24. Li, H. etal. Isolation and characterization of H5N1 and H9N2 influenza viruses from pigs in China [in Chinese]. Chin. J. Prev. Vet. Med. 26, 1-6 (2004).

25. Nidom, C. A. et al. Influenza A (H5N1) viruses from pigs, Indonesia. Emerg. Infect Dis. 16, 1515-1523 (2010)

26. Pasma, T.\& Joseph, T. Pandemic (H1N1) 2009 infection in swine herds, Manitoba, Canada. Emerg. Infect. Dis. 16, 706-708 (2010).

27. Pereda, A. et al. Pandemic (H1N1) 2009 outbreak on pig farm, Argentina. Emerg. Infect. Dis. 16, 304-307 (2010)

28. Welsh, M. D. et al. Initial incursion of pandemic (H1N1) 2009 influenza A virus into European pigs. Vet. Rec. 166, 642-645 (2010).

29. Xu, Q., Wang, W., Cheng, X., Zengel, J. \& Jin, H. Influenza H1N1 A/Solomon Island/ $3 / 06$ virus receptor binding specificity correlates with virus pathogenicity, antigenicity, and immunogenicity in ferrets. J. Virol. 84, 4936-4945 (2010).

30. van Riel, D. et al. Human and avian influenza viruses target different cells in the lower respiratory tract of humans and other mammals. Am. J. Pathol. 171, 1215-1223 (2007).

31. Gao, Y. et al. Identification of amino acids in HA and PB2 critical for the transmission of $\mathrm{H} 5 \mathrm{~N} 1$ avian influenza viruses in a mammalian host. PLoS Pathog. 5, e1000709 (2009).

32. Itoh, Y. etal. In vitro and in vivo characterization of new swine-origin H1N1 influenza viruses. Nature 460, 1021-1025 (2009)

33. Skehel, J. J. \& Wiley, D. C. Receptor binding and membrane fusion in virus entry: the influenza hemagglutinin. Annu. Rev. Biochem. 69, 531-569 (2000).

34. England, R. J., Homer, J. J., Knight, L. C. \& Ell, S. R. Nasal pH measurement: a reliable and repeatable parameter. Clin. Otolaryngol. Allied Sci. 24, 67-68 (1999).

35. Carr, C. M., Chaudhry, C. \& Kim, P. S. Influenza hemagglutinin is spring-loaded by a metastable native conformation. Proc. Natl Acad. Sci. USA 94, 14306-14313 (1997).

36. Haywood, A. M. \& Boyer, B.P. Time and temperature dependence of influenza virus membrane fusion at neutral pH. J. Gen. Virol. 67, 2813-2817 (1986)

37. Krenn, B. M. et al. Single HA2 mutation increases the infectivity and immunogenicity of a live attenuated $\mathrm{H} 5 \mathrm{~N} 1$ intranasal influenza vaccine candidate lacking NS1. PLoS ONE 6, e18577 (2011).

38. Treanor, J. J., Campbell, J. D., Zangwill, K. M., Rowe, T. \& Wolff, M. Safety and immunogenicity of an inactivated subvirion influenza A (H5N1) vaccine. N. Engl. J. Med. 354, 1343-1351 (2006)

39. Bussey, K. A., Bousse, T. L., Desmet, E. A., Kim, B. \& Takimoto, T. PB2 residue 271 plays a key role in enhanced polymerase activity of influenza $A$ viruses in mammalian host cells. J. Virol. 84, 4395-4406 (2010).

40. Hatta, M., Gao, P., Halfmann, P. \& Kawaoka, Y. Molecular basis for high virulence of Hong Kong H5N1 influenza A viruses. Science 293, 1840-1842 (2001)

41. Li, Z. et al. Molecular basis of replication of duck H5N1 influenza viruses in a mammalian mouse model. J. Virol. 79, 12058-12064 (2005)

42. Mehle, A. \& Doudna, J. A. Adaptive strategies of the influenza virus polymerase for replication in humans. Proc. Natl Acad. Sci. USA 106, 21312-21316 (2009).

43. Yamada, S. et al. Biological and structural characterization of a host-adapting amino acid in influenza virus. PLoS Pathog. 6, e1001034 (2010).

44. Salzberg, S. L. et al. Genome analysis linking recent European and African influenza (H5N1) viruses. Emerg. Infect. Dis. 13, 713-718 (2007).

45. Subbarao, E. K., London, W. \& Murphy, B. R. A single amino acid in the PB2 gene of influenza A virus is a determinant of host range. J. Virol. 67, 1761-1764 (1993).

Supplementary Information is linked to the online version of the paper at www.nature.com/nature.

Acknowledgements The authors would like to acknowledge D. Holtzman for his contributions to the initial concept for this project and thoughtful scientific discussions. We thank M. McGregor, R. Moritz, L. Burley, K. Moore, A. Luka, J. Bettridge, N. Fujimoto and $\mathrm{M}$. Ito for technical support, S. Watson for editing the manuscript, and the National Institute of Hygiene and Epidemiology, Hanoi, Vietnam for the A/Vietnam/1203/2004 (H5N1) virus, which was obtained from the CDC. This work was supported by the Bill \& Melinda Gates Foundation (Grants 48339 and OPPGH5383), by a Grant-in-Aid for Specially Promoted Research from the Ministry of Education, Culture, Sports, Science, and Technology of Japan, by ERATO (Japan Science and Technology Agency), and by the National Institute of Allergy and Infectious Diseases Public Health Service Research grants. The following reagents were obtained from the $\mathrm{NIH}$ Biodefense and Emerging Infections Research Resources Repository, NIAID, NIH: polyclonal anti-monovalent influenza subvirion vaccine rgA/Vietnam/1203/2004 (H5N1), (antiserum, Human), high tire pool, NR-4109 and low titre pool, NR-4110.

Author Contributions M.I., T.W., M.H., S.C.D., M.O., K.S., G.Z., A.H., H.K., S.W., C.L., S.Y., M.K., Y.S., E.A.M., G.N. and Y.K. designed the experiments; M.I., T.W., M.H., S.C.D., M.O., K.S., G.Z., A.H., H.K., S.W., C.L., S.Y. and M.K. performed the experiments; M.I., T.W., M.H S.C.D., M.O., K.S., G.Z., A.H., H.K., S.W., C.L., E.K., S.Y., M.K., Y.S., E.A.M., G.N. and Y.K. analysed the data; M.I., T.W., M.H., S.C.D., K.S., E.A.M., G.N. and Y.K. wrote the manuscript; M.I., T.W. and M.H. contributed equally to this work.

Author Information Reprints and permissions information is available at www.nature.com/reprints. This paper is distributed under the terms of the Creative Commons Attribution-Non-Commercial-Share Alike licence, and is freely available to all readers at www.nature.com/nature. The authors declare competing financial interests: details accompany the full-text HTML version of the paper at www.nature.com/nature. Readers are welcome to comment on the online version of this article at www.nature.com/nature. Correspondence and requests for materials should be addressed to Y.K. (kawaokay@svm.vetmed.wisc.edu). 


\section{METHODS}

Cells. Madin-Darby canine kidney (MDCK) cells and MDCK cells overexpressing Sia $2,6 \mathrm{Gal}\left(\mathrm{AX} 4\right.$ cells $\left.^{17}\right)$ were maintained in Eagle's minimal essential medium (MEM) containing 5\% newborn calf serum. Human embryonic kidney $293 \mathrm{~T}$ cells were cultured in Dulbecco's modified Eagle's medium containing $10 \%$ fetal bovine serum (FBS). HeLa cells were maintained in MEM containing 10\% FBS. All cells were maintained at $37^{\circ} \mathrm{C}$ in $5 \% \mathrm{CO}_{2}$.

Plasmid construction and reverse genetics. Plasmid constructs for viral RNA production (pPolI) — containing the genes of the A/Vietnam/1203/2004 (H5N1; VN1203), A/Puerto Rico/8/34 (H1N1; PR8), A/Kawasaki/173/2001 (H1N1; K173) and A/California/04/2009 (H1N1; CA04) viruses flanked by the human RNA polymerase I promoter and the mouse RNA polymerase I terminator-were constructed as described ${ }^{16}$. The multibasic amino acids at the haemagglutinin (HA) cleavage site (RERRRKKR $\downarrow G)$ of the reassortant viruses between VN1203 and PR8 were changed to RETR $\downarrow G$ by site-directed mutagenesis. All transfectant viruses were generated by using reverse genetics essentially as described previously ${ }^{16}$. Recombinant viruses were amplified in MDCK or AX ${ }^{17}$ cells and stored at $-80^{\circ} \mathrm{C}$ until use. The HA segment of all viruses was sequenced to ensure the absence of unwanted mutations. All experiments with the reassortant viruses between VN1203 and CA04 were performed in enhanced biosafety level 3 containment laboratories approved for such use by the CDC and the USDA.

To introduce random mutations into the globular head of the VN1203 HA protein, a 143-amino-acid region spanning residues 120-259 (H3 numbering) was selected. This region was subjected to PCR-based random mutagenesis by use of the GeneMorph II kit (Stratagene) following the manufacturer's instructions. The targeted mutation rate (1-2 amino acid replacements per molecule) was achieved through optimization of the template quantity, and was confirmed by sequence analysis of 48 individual clones. By using a PCR-based cloning strategy, we inserted the mutagenized region into its respective vector containing the VN1203 HA gene between the human RNA polymerase I promoter and mouse RNA polymerase I terminator sequences. The composition of the plasmid library was confirmed by sequencing. The plasmid library was then used to generate an influenza virus library, essentially as described ${ }^{16}$. The size of the virus library was $7 \times 10^{6}$ p.f.u.

Preparation of sialidase-treated TRBCs. Turkey red blood cells (TRBCs) were washed three times with phosphate-buffered saline (PBS), and diluted to $20 \%$ (vol/ vol) in PBS. TRBCs $(1 \mathrm{ml})$ were incubated with $500 \mathrm{U}$ of $\alpha 2,3$-sialidase from Salmonella enterica serovar Typhimurium LT2 (NEB) for $20-24 \mathrm{~h}$ at $37^{\circ} \mathrm{C}$, washed three times in PBS, and re-suspended in PBS or MEM containing 1\% bovine serum albumin (BSA) (MEM/BSA)

Haemagglutination assay. Viruses $(50 \mu \mathrm{l})$ were serially diluted with $50 \mu \mathrm{l}$ of PBS in a microtitre plate. An equal volume (that is, $50 \mu \mathrm{l}$ ) of a $0.5 \%$ (vol/vol) TRBC suspension was added to each well. The plates were kept at room temperature and haemagglutination was assessed after a 1-h incubation.

Virus library screening. To select VN1203 HA variants that had acquired the ability to recognize human-type receptors, three parallel experiments were carried out, each with $0.7 \times 10^{6}$ viruses. The virus library was first incubated with $0.1 \mathrm{ml}$ of $10 \%$ (vol/vol) $\alpha 2,3$-sialidase-treated TRBCs for $10 \mathrm{~min}$ at $4{ }^{\circ} \mathrm{C}$. After this incubation, the TRBCs and bound viruses were pelleted at 1,000 r.p.m. for $1 \mathrm{~min}$, and the pellets then washed ten times in MEM/BSA containing $313 \mathrm{mM} \mathrm{NaCl}$. Bound viruses were eluted by incubation at $37^{\circ} \mathrm{C}$ for $30 \mathrm{~min}$ and then diluted to approximately 0.5 virus per well (determined by virus titration in a pilot study). Individual viruses were then amplified in AX4 cells, which overexpress Sia $\alpha 2,6 \mathrm{Gal}^{17}$. Individual viruses were re-screened by using haemagglutination assays with $\alpha 2,3$-sialidase-treated TRBCs.

Solid-phase binding assay. Viruses were grown in MDCK cells, clarified by lowspeed centrifugation, laid over a cushion of $30 \%$ sucrose in PBS, and ultracentrifuged at 25,000 r.p.m. for $2 \mathrm{~h}$ at $4{ }^{\circ} \mathrm{C}$. Virus stocks were aliquoted and stored at $-80^{\circ} \mathrm{C}$. Virus concentrations were determined by using haemagglutination assays with $0.5 \%$ ( vol $/ \mathrm{vol}$ ) TRBCs. The direct receptor-binding capacity of viruses was examined by use of a solid-phase binding assay as previously described ${ }^{9}$. Microtitre plates (Nunc) were incubated with the sodium salts of sialylglycopolymers (polyL-glutamic acid backbones containing $\mathrm{N}$-acetylneuraminic acid linked to galactose through either an $\alpha 2,3$ (Neu5Ac $\alpha 2,3 \mathrm{Gal} \beta 1,4 \mathrm{GlcNAc} \beta 1-\mathrm{pAP}$ ) or an $\alpha 2,6$ (Neu5Ac $\alpha 2,6 \mathrm{Gal} \beta 1,4 \mathrm{GlcNAc} \beta 1$-pAP) bond) in PBS at $4{ }^{\circ} \mathrm{C}$ overnight. After the glycopolymer solution was removed, the plates were blocked with $0.15 \mathrm{ml}$ of PBS containing $4 \% \mathrm{BSA}$ at room temperature for $1 \mathrm{~h}$. After four successive washes with ice-cold PBS, the plates were incubated in a solution containing influenza virus (8$32 \mathrm{HA}$ units in PBS) at $4{ }^{\circ} \mathrm{C}$ overnight. After washing as described above, the plates were incubated for $2 \mathrm{~h}$ at $4{ }^{\circ} \mathrm{C}$ with rabbit polyclonal antiserum to either $\mathrm{K} 173$ or VN1203 virus. The plates were then washed again as before and incubated with horseradish peroxidase (HRP)-conjugated goat anti-rabbit IgG antiserum for $2 \mathrm{~h}$ at $4{ }^{\circ} \mathrm{C}$. After washing, the plates were incubated with $\mathrm{O}$-phenylenediamine
(Sigma) in PBS containing $0.01 \% \mathrm{H}_{2} \mathrm{O}_{2}$ for $10 \mathrm{~min}$ at room temperature, and the reaction was stopped with $0.05 \mathrm{ml}$ of $1 \mathrm{M} \mathrm{HCl}$. The optical density at $490 \mathrm{~nm}$ was determined in a plate reader (Infinite M1000; Tecan).

Virus binding to human airway tissues. Paraffin-embedded normal human trachea (US Biological) and lung (BioChain) tissue sections were deparaffinized and rehydrated. Sections were then blocked by using $4 \%$ BSA in PBS and covered with virus suspensions (64 HA units in PBS) at $4{ }^{\circ} \mathrm{C}$ overnight. After being washed four times in ice-cold PBS, the sections were incubated with primary antibodies for $3 \mathrm{~h}$ at $4{ }^{\circ} \mathrm{C}$. The primary antibodies used were as follows: a pool of mouse anti-VN1203 HA monoclonal antibodies (15A3, 3G2, 7A11, 8A3, 14C5 and 18E1; Rockland); rabbit anti-K173 polyclonal antibody; rabbit antisurfactant protein A polyclonal antibody (Millipore); and mouse antisurfactant protein A monoclonal antibody (Abcam). Antibody binding was detected by using an IgG secondary antibody conjugated with Alexa Fluor 488 or Alexa Fluor 633 (Molecular Probes). Sections were also counterstained with Hoechst 33342, trihydrochloride, trihydrate (Molecular Probes). The samples were examined by using confocal laser scanning microscopy (model LSM 510; Carl Zeiss)

To confirm sialic-acid-specific virus binding, tissue sections were treated, before incubation with viruses, with Arthrobacter ureafaciens sialidase (Sigma) for $3 \mathrm{~h}$ at $37^{\circ} \mathrm{C}$. Viruses bound to tissue were detected as described above.

Experimental infection of ferrets. Animal studies were performed in accordance with the Animal Care and Use Committee guidelines of the University of WisconsinMadison. We used 6-10-month-old female ferrets (Triple F Farms) that were serologically negative by haemagglutination inhibition (HI) assay for currently circulating human influenza viruses. Six ferrets per group were anaesthetized intramuscularly with ketamine and xylazine $\left(5-30 \mathrm{mg}\right.$ and $0.2-6 \mathrm{mg} \mathrm{kg}^{-1}$ of body weight, respectively) and inoculated intranasally with $10^{6}$ p.f.u. (500 $\mu \mathrm{l}$ ) of viruses On days 3 and 6 after infection, three ferrets per group were killed for virological and pathological examinations. The virus titres in various organs were determined by use of plaque assays in MDCK cells.

Excised tissue samples of nasal turbinates, trachea, lungs, brain, liver, spleen, kidney and colon from euthanized ferrets were preserved in $10 \%$ phosphatebuffered formalin. Tissues were then trimmed and processed for paraffin embedding and cut into 5 - $\mu \mathrm{m}$-thick sections. One section from each tissue sample was stained by using a standard haematoxylin-and-eosin procedure, whereas another one was processed for immunohistological staining with a mixture of two anti-influenza virus rabbit antibodies (1:2,000; R309 and anti-VN1203; both prepared in our laboratory) that react with CA04 and VN1203, respectively. Specific antigen-antibody reactions were visualized by using an indirect twostep dextran-polymer technique (Dako EnVision system; Dako) and 3,3' diaminobenzidine tetrahydrochloride staining (Dako).

Ferret transmission study. For transmission studies in ferrets, animals were housed in adjacent transmission cages that prevented direct and indirect contact between animals but allowed spread of influenza virus through the air (Showa Science; Supplementary Fig. 7). Three, five, or six ferrets were inoculated intranasally with $10^{6}$ p.f.u. (500 $\mu \mathrm{l}$ ) of virus (inoculated ferrets). Twenty-four hours after infection, three, five, or six naive ferrets were each placed in a cage adjacent to an inoculated ferret (contact ferrets). The ferrets were monitored for changes in body weight and the presence of clinical signs. To assess viral replication in nasal turbinates, we determined viral titres in nasal washes collected from virusinoculated and contact ferrets on day 1 after inoculation or co-housing, respectively, and then every other day.

Serological tests. Serum samples were collected between days 14 and 20 after infection, treated with receptor-destroying enzyme, heat-inactivated at $56{ }^{\circ} \mathrm{C}$ for $30 \mathrm{~min}$ and tested by use of an $\mathrm{HI}$ assay with $0.5 \% \mathrm{TRBCs}$ (http://www.wpro.who.int/entity/ emerging diseases/documents/docs/manualonanimalaidiagnosisandsurveillance. pdf). Viruses bearing homologous HA were used as antigens for the HI tests.

Polykaryon formation representing membrane fusion activity. Monolayers of HeLa cells grown in 12-well plates were transfected with the protein expression vector pCAGGS ${ }^{46}$ encoding wild-type or mutant HA. At $24 \mathrm{~h}$ after transfection, cells transiently expressing HA protein were treated with trypsin $\left(1 \mu \mathrm{g} \mathrm{ml}^{-1}\right)$ in MEM containing $0.3 \% \mathrm{BSA}$ for $30 \mathrm{~min}$ at $37^{\circ} \mathrm{C}$ to cleave the HA into its $\mathrm{HA} 1$ and HA2 subunits. Polykaryon formation was induced by exposing the cells to low-pH buffer $(145 \mathrm{mM} \mathrm{NaCl}, 20 \mathrm{mM}$ sodium citrate $(\mathrm{pH} 6.0-5.4))$ for $2 \mathrm{~min}$ at $37^{\circ} \mathrm{C}$ After this exposure, the low-pH buffer was replaced with MEM containing 10\% FBS and the cells were incubated for $3 \mathrm{~h}$ at $37^{\circ} \mathrm{C}$. The cells were then fixed with methanol and stained with Giemsa's solution and photographed with a digital camera mounted on an inverted microscope (Nikon, Eclipse Ti). For quantitative analyses, cell nuclei were counted in five randomly chosen fields of cell culture. Polykaryon formation activity was calculated from the number of nuclei in polykaryons divided by the total number of nuclei in the same field. 


\section{RESEARCH LETTER}

Thermostability. Viruses (128 HA units in PBS) were incubated for the times indicated at $50{ }^{\circ} \mathrm{C}$. Subsequently, infectivity and haemagglutination activity were determined by use of plaque assays in MDCK cells and haemagglutination assays using $0.5 \%$ TRBCs, respectively.

Neuraminidase (NA) inhibition assay. To assess the sensitivity of viruses to the NA inhibitor oseltamivir, NA inhibition assays were performed as described previously ${ }^{32}$.
Statistical analysis. All statistical analyses were performed using JMP 9.0.0 (SAS Institute Inc.). The statistical significance of differences between rgCA04 and H5 avian/human reassortant viruses was determined by using a Dunnett's test. Comparisons of polykaryon formation between wild-type and mutant HAs were done using Tukey's test. $P$ values of $<0.05$ were considered significant.

46. Niwa, H., Yamamura, K. \& Miyazaki, J. Efficient selection for high-expression transfectants with a novel eukaryotic vector. Gene 108, 193-199 (1991). 